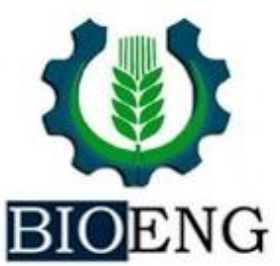

\title{
PRODUTIVIDADE DE CAPIM-MOMBAÇA (Panicum maximum), COM DIFERENTES DOSES DE BIOFERTILIZANTE
}

UNIARA - Centro Universitário de Araraquara, Engenharia Agronômica, Araraquara, SP, Brasil

Article history: Received 28 January 2016; Received in revised form 10 March 2016; Accepted 14 March 2016; Available online 21 March 2016.

\section{RESUMO}

O presente estudo teve por objetivo verificar a influência da aplicação do dejeto de bovino leiteiro tratados em biodigestores anaeróbios, na forma de biofertilizante, sobre a produtividade da capim Mombaça, em condições de sequeiro. O trabalho foi conduzido no Instituto de Biotecnologia - IBIOTEC, pertencente à UNIARA, Araraquara - SP. Para obtenção do biofertilizante, foi feita a diluição dos dejetos em água e armazenado em um biodigestor modelo indiano de fibra de vidro com capacidade útil de $1000 \mathrm{~L}$, instalado no referido instituto. As fertilizações foram feitas a lanço após cada rebaixamento das parcelas. O delineamento utilizado foi em blocos casualizados, com quatro tratamentos e quatro repetições, com diferentes doses do biofertilizante, sendo: $0 ; 50 \mathrm{~m}^{3} ; 100 \mathrm{~m}^{3}$ e $200 \mathrm{~m}^{3} / \mathrm{ha}^{-1}$. As variáveis avaliadas foram: altura, produção por hectare (matéria seca e matéria verde), e qualidade bromatológica. Foram observados que os tratamentos que receberam a maior dosagem de biofertilizante, apresentaram maiores valores para produtividade Matéria Seca, Matéria Verde e teor de proteína. Conclui-se que a aplicação de biofertilizante é benéfico ao sistema de pastagem, porém suas doses devem ser estudadas e a sua resposta na produção pode obtidas a longo prazo.

Palavras-chave: Adubação orgânica, aproveitamento de resíduos e forragem.

\section{MOMBAÇA GRASS PRODUCTIVITY (Panicum maximum), WITH DIFFERENT DOSES OF BIOFERTILIZER}

\begin{abstract}
This study aimed to verify the influence of the application of dairy cattle manure treated in biodigesters anaerobics, in the form of biofertilizer on the productivity of grass Mombaca, upland conditions. The work was conducted at the Institute of Biotechnology - IBIOTEC belonging to UNIARA, Araraquara - SP. To obtain the fertilizer was taken dilution of waste water and stored in a digester Indian model fiberglass with a useful capacity of $1000 \mathrm{~L}$, installed in refer institute. The fertilizations were made to haul after each lowering of the plots. The design was a randomized complete block $\mathrm{d}$ with four treatments and four replications, with different doses of biofertilizers, as follows: $0 ; 50 \mathrm{~m}^{3} ; 100 \mathrm{~m}^{3}$ and $200 \mathrm{~m}^{3} /$ ha. The variables were: height,

\footnotetext{
*laurahcosta@yahoo.com.br

Parte do Trabalho de Conclusão de Curso em Engenharia Agronômica, Uniara.
} 
per hectare production (dry matter and green matter), and chemical quality. They observed that the treatments that received the highest dose of biofertilizer, showed higher values for productivity Dry Matter, Green Matter and protein. It follows that the application of biofertilizers is beneficial to the pasture system, but their doses should be studied and their response in production can obtained the long run.

Keywords: Forage, organic manure and waste recovery

\section{INTRODUÇÃO}

Uma característica importante da pecuária brasileira é ter a maior parte de seu rebanho bovino criado a pasto, constituindo-se na forma mais econômica e prática de produzir e oferecer alimentos nas condições tropicais, e pelas vantagens do manejo mais fácil em relação às forragens processadas ou conservadas.

EUCLIDES et al., (2010), em seu trabalho sobre o progresso das pastagens, afirma que cerca de $90 \%$ dos nutrientes necessários pelos ruminantes são obtidos diretamente através do pastejo.

Dentre as espécies de plantas forrageiras mais utilizados no pastejo de bovinos, destaca-se Panicum maximum Jacq, cujos cultivares têm significativo valor em nossas pastagens e, nos últimos anos, têm tido uso crescente na pecuária nacional (GOMES, 2001).

O capim Mombaça (Panicum maximum Jacq.), é considerado uma das forrageiras tropicais mais produtivas à disposição dos pecuaristas. Dados de literaturas relatam que pastagens em situações de baixa fertilidade, a produção é reduzida, caracterizando a exigência do capim Mombaça em fertilidade do solo (Freitas et al. 2007). $\mathrm{O}$ uso racional de adubos orgânicos e ou corretivos, a resposta da forrageira é bastante acentuada para seu uso como pastejo.

Atualmente, os sistemas de produção animal a base de pasto tem buscado modelos de produção sustentáveis, baseados na melhoria da qualidade do solo. De um modo geral, no Brasil, o desenvolvimento de sistemas de produção animal agroecológicos ou orgânicos tem sido mais lento que a produção vegetal nestes sistemas TINOCO et. al (2009).

De acordo com HANISCH E FONSECA (2011), na perspectiva desta mudança de cenário, a questão dos dejetos animais surge como uma possibilidade de uso em sistemas de produção. Esses dejetos, quando adequadamente armazenados e corretamente utilizados, podem fornecer nutrientes para as plantas e ainda melhorar consideravelmente as condições físicas, químicas e biológicas do solo propiciando maior infiltração e retenção de água e maior aeração no solo.

ARAÚJO et al. (2008), em seu trabalho comparou a eficiência de diferentes fontes de matéria orgânica na produtividade do Panicum maximum cv. Mombaça, e evidenciaram que a utilização da adubação orgânica melhorou as características químicas do solo, além de proporcionar maior produtividade do capim-Mombaça.

Neste sentido, trabalhos envolvendo estudos com uso de fontes orgânicas como o biofertilizante são necessários, para que se preconize ou haja uma premissa do seu uso de forma racional nos diversos sistemas de produção animal, gerando melhor aproveitamento desses resíduos e propiciando maior sustentabilidade a estes sistemas, principalmente na bovinocultura de leite.

O presente trabalho objetivou avaliar a influência da adubação orgânica na forma de biofertilizante de 
dejeto de gado leiteiro com diferentes doses de aplicação sobre as características produtivas e qualitativas

\section{MATERIAL E MÉTODOS}

O experimento foi conduzido no Instituto de Biotecnologia - IBIOTEC, em área pertencente à unidade demonstrativa de produção de leite AEQUITAS Departamento de Engenharia Agronômica - UNIARA Araraquara - SP, onde o pasto foi formado em 2011. O solo da região é do tipo rochoso sedimentar com predominância vermelho argiloso

A classificação climática para a região, segundo Köppen, é do tipo Cwa, ou seja, subtropical úmido caracterizado por duas estações bem definidas; um verão com temperaturas altas (média de $31^{\circ} \mathrm{C}$ ) e pluviosidade elevada e um inverno de temperaturas amenas e pluviosidade reduzida, com precipitação média anual situando-se próxima de $1.300 \mathrm{~mm}$ e 21 a $23^{\circ} \mathrm{C}$, respectivamente.

A variedade de capim utilizado foi Panicum maximum Jacq., as quais já estavam em formação de pastejo com idade de 28 meses, no instituto de biotecnologia - IBIOTEC cidade de Araraquara - SP.

Para alimentação do biodigestor os dejetos foram coletados no local de descanso e ordenha das vacas, o qual foi misturado com água para homogeneização na proporção $2: 1$, e armazenado em um biodigestor modelo indiano de fibra de vidro com capacidade útil de $1000 \mathrm{~L}$, instalado no de pastagens do gênero Panicum Maximum Jacq. cv Mombaça.

instituto de biotecnologia - IBIOTEC cidade de Araraquara - SP. As características químicas do biofertilizante era de 4 $\%$ de sólidos totais e $\mathrm{pH}$ próximo a neutralidade em torno de 6,3.

O delineamento utilizado foi o de blocos casualizados com 4 tratamentos, sendo 4 repetições, onde eram 3 doses de biofertilizantes e uma testemunha, totalizam 16 parcelas. O espaçamento entre as parcelas eram de $0,5 \mathrm{~m}$ e o descarte da área total em bordadura foi de $1,25 \mathrm{~m}$, com um total de área de 324 $\mathrm{m}^{2}$.

As descrições dos tratamentos bem como as composições e proporções do biofertilizante que foram utilizados foi: Tratamento 1 Controle (0); Tratamento 2 com $50 \mathrm{~m}^{3} \mathrm{de}$ biofertilizante (50), Tratamento 3 com $100 \mathrm{~m}^{3}$ de biofertilizante (100) e tratamento 4 com $200 \mathrm{~m}^{3}$ de biofertilizante (200).

\section{Dados climatológicos}

Uma vez que toda a produtividade da pastagem depende de índices hídricos, durante a realização do experimento, foi feito um acompanhamento dos dados pluviométricos da região, onde foram coletados na própria área experimental. Como mostra a Figura 1. 


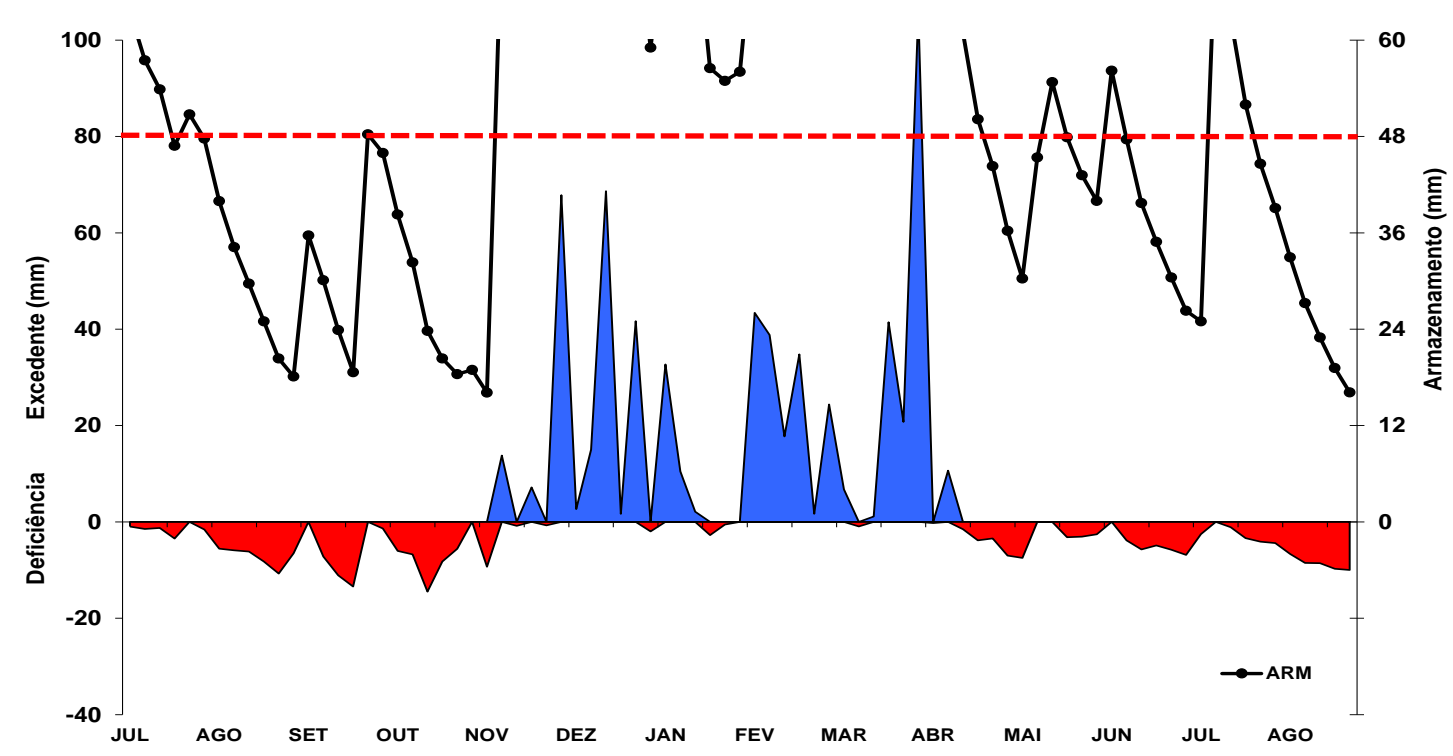

Figura 1- Balanço Hídrico da área durante o experimento

No que diz respeito ao regime hídrico, as pastagens podem ser classificadas em pastagens de sequeiro se beneficiam para a sua produção apenas da água que é proveniente da precipitação que ocorre, sendo que a escassez e a irregularidade, limitam o seu potencial produtivo. Já no caso o regadio permite através do fornecimento de água, a constituição de pastagens, com uma oferta alimentar quantitativamente superior e mais regular ao longo do ano.

Pela figura 1, no período de julho a começo de novembro houve um déficit hídrico, sendo restabelecido no período de fim de novembro a abril, onde a chuva que ocorreu conseguiu suprir a necessidade do solo e tendo um armazenamento de água no mesmo, já no período de maio a agosto, ocorreu novamente um déficit, mesmo com períodos de chuvas não conseguiram suprir a necessidade do solo e da planta.

\section{Parâmetros Avaliados \\ Produtividade}

Os parâmetros avaliados durante a realização do experimento foram:

- Altura (A): onde foi feito a aferição utilizando uma régua de madeira graduada em $\mathrm{cm}$, medindo-se desde sua base rente ao solo até a extremidade apical da folha.

- Produção (P): era realizado corte de todas as plantas do tratamento, em seguida eram pesadas, para quantificar a massa verde e posteriormente seca, em estufa a $60^{\circ} \mathrm{c}$ com tempo mínimo de 72 horas para quantificar a produção de matéria seca por hectare.

Para as avaliações de altura e produção foi usado um quadrado amostrador de $1 \mathrm{~m}^{2}$, jogado aleatoriamente nas parcelas e a mesma eram feitas cortando a forragem acima da altura do resíduo (30 $\mathrm{cm}$ de altura), em cada coleta eram feitas 2 subamostras, por parcela, após eram misturas e homogeneizadas e retirada uma amostra em torno de 200 a 300 gramas, para quantificar a resposta de produção de matéria seca por hectare. $\mathrm{E}$ logo após a coleta eram feitos o rebaixamento de todas as parcelas deixando-as na altura do resíduo, utilizando uma roçadeira costal.

As fertilizações foram feitas após cada rebaixamento das parcelas, ou seja, a cada 30 dias durante o período de julho de 2014 a agosto de 2015, portanto foi necessário mudar a data das coletas se a altura da forragem não atingisse a altura do resíduo $(30 \mathrm{~cm})$. 
Análise Bromatológica

As análises bromatológicas propostas, foram realizadas no laboratório de Biomassa da FCAV/UNESP - Jaboticabal. As amostras coletadas para produção de massa, foram acondicionadas em sacos de papel para secagem, e os parâmetros avaliados foram: teores de proteína, fibra em detergente neutro (FDN), fibra em detergente ácido (FDA), que foram feitas a partir das amostras secas em

\section{RESULTADOS E DISCUSSÕES}

\section{Altura da Planta}

Os resultados de altura obtidos, encontram-se na Tabela 1, verifica-se que no primeiro período os tratamentos 1,3 e 4 foram estatisticamente iguais, e estufa, moídas em moinho tipo Wiley com peneira de malha de $1.00 \mathrm{~mm}$, segundo metodologia de Silva (2002), e do método convencional de Van Soest (1964, 1991), respectivamente.

\section{Análise Estatística}

Os dados obtidos foram submetidos à análise de variância e as médias comparadas pelo teste de Tukey a $5 \%$ de probabilidade, utilizando o programa estatístico SASM AGRI.

o tratamento 2 diferiu estatisticamente do tratamento 1, possivelmente pelo fato do tratamento 1 não ter recebido nenhuma suplementação.

Tabela 1. Altura da planta $(\mathrm{cm})$

\begin{tabular}{cccccc}
\hline \multirow{2}{*}{ Tratamentos Períodos avaliados (data) } \\
\cline { 2 - 6 } & $20 / 12 / 2014$ & $26 / 01 / 2015$ & $01 / 03 / 2015$ & $03 / 04 / 2015$ & $09 / 05 / 2015$ \\
\hline 0 & $76,0 \mathrm{~b}$ & $53,0 \mathrm{~b}$ & $59,5 \mathrm{~b}$ & $52,5 \mathrm{c}$ & $54,8 \mathrm{~b}$ \\
50 & $93,3 \mathrm{a}$ & $56,0 \mathrm{ab}$ & $70,9 \mathrm{a}$ & $63,5 \mathrm{ab}$ & $60,9 \mathrm{ab}$ \\
100 & $89,8 \mathrm{ab}$ & $52,8 \mathrm{~b}$ & $71,3 \mathrm{a}$ & $60,9 \mathrm{~b}$ & $60,3 \mathrm{ab}$ \\
200 & $87,0 \mathrm{ab}$ & $61,8 \mathrm{a}$ & $74,8 \mathrm{a}$ & $67,3 \mathrm{a}$ & $62,5 \mathrm{a}$ \\
\hline CV \% & 7,8 & 5,3 & 4,3 & 4,4 & 4,7 \\
\hline
\end{tabular}

Médias seguidas pela mesma letra na mesma coluna não diferem entre si a $5 \%$ de probabilidade pelo teste de Tukey.

Os resultados encontrados nesse trabalho, corroboram com os de SCHEFFER-BASSO et al. (2008), que utilizou efluente de suinocultura, encontrou crescimento linear na altura das plantas na maior dose, as plantas foram $21 \mathrm{~cm}$ maiores que as plantas que não tiveram nenhuma suplementação.

$\mathrm{Na}$ segunda aplicação em diante, foi observado que o tratamento com 200 $\mathrm{m}^{3}$ que recebeu maior dose de biofertilizante, diferiu estatisticamente dos demais tratamentos apresentando maiores valores de para crescimento (cm), evidenciando que houve influência do biofertilizante para o crescimento da forragem que pode ser notado, pois todos os tratamentos que receberam biofertilizante diferiram estatisticamente do tratamento controle.

Relatos do trabalho de HANISCH \& FONSECA (2011), afirmam que fontes orgânicas parecem causar imobilização de nutrientes do solo no primeiro mês após sua incorporação. Depois desse período, a liberação aumenta progressivamente, atingindo as maiores quantidades entre três e seis meses após a incorporação. Por outro lado, a disponibilidade imediata dos nutrientes nas fontes minerais é maior do que nos estercos. E isso pode ser observado nos dados da tabela 1, após a 
segunda aplicação, onde houve crescimento notório na forragem.

\section{Produtividade}

Para a produtividade de massa verde (Tabela 2), em todos os períodos avaliados o tratamento 4, com a maior dose de biofertilizante, obteve maior valor, porém não diferindo estatisticamente dos tratamentos 2 e 3 mas diferindo do tratamento 1 , isso pode ser respondido pelo fato que quanto maior volume de biofertilizante, com o tempo maior vai ser o volume de nutrientes disponibilizado para a planta.

Tabela 2. Produtividade de massa verde $\left(\mathrm{kg} \mathrm{ha}^{-1}\right)$

\begin{tabular}{cccccc}
\hline \multirow{2}{*}{ Tratamentos } & \multicolumn{5}{c}{ Períodos avaliados (data) } \\
\cline { 2 - 6 } & $20 / 12 / 2014$ & $26 / 01 / 2015$ & $01 / 03 / 2015$ & $03 / 04 / 2015$ & $09 / 05 / 2015$ \\
\hline 1 & $2770,0 \mathrm{~b}$ & $985,0 \mathrm{~b}$ & $1300,0 \mathrm{~b}$ & $995,0 \mathrm{~b}$ & $645,0 \mathrm{~b}$ \\
2 & $3501,3 \mathrm{ab}$ & $1526,3 \mathrm{ab}$ & $2356,3 \mathrm{ab}$ & $1380,0 \mathrm{ab}$ & $856,3 \mathrm{ab}$ \\
3 & $3442,5 \mathrm{ab}$ & $1208,8 \mathrm{ab}$ & $2278,8 \mathrm{ab}$ & $1480,0 \mathrm{ab}$ & $942,5 \mathrm{ab}$ \\
4 & $3946,3 \mathrm{a}$ & $1815,0 \mathrm{a}$ & $2775,0 \mathrm{a}$ & $1902,5 \mathrm{a}$ & $1325,0 \mathrm{a}$ \\
\hline CV \% & 11,3 & 20,0 & 27,7 & 18,61 & 27,51 \\
\hline
\end{tabular}

Médias seguidas pela mesma letra na mesma coluna não diferem entre si a 5\% de probabilidade pelo teste de Tukey.

Os dados de BARNABÉ (2001), avaliando a fertirrigação de capimmarandú com efluentes de suinocultura, utilizando doses de $\left(50,100\right.$ e $150 \mathrm{~m}^{3}$ $\mathrm{ha}^{-1}$ ) observou que a aplicação de 150 $\mathrm{m}^{3} \mathrm{ha}^{-1}$ em substituição à adubação química foi a que promoveu os foram encontrados nesse trabalho onde aqueles tratamentos com maior dose de fertilizante apresentou maior média.

Para a produtividade de massa seca (Tabela 3), todos os períodos avaliados o tratamento 4 foi estatisticamente superior ao tratamento 1 , não diferindo dos tratamentos 2 e 3 .

Tabela 3. Produtividade de massa seca $\left(\mathrm{kg} \mathrm{ha}^{-1}\right)$

\begin{tabular}{cccccc}
\hline \multirow{2}{*}{ Tratamentos Períodos avaliados (data) } \\
\cline { 2 - 6 } & $20 / 12 / 2014$ & $26 / 01 / 2015$ & $01 / 03 / 2015$ & $03 / 04 / 2015$ & $09 / 05 / 2015$ \\
\hline 1 & $887,0 \mathrm{~b}$ & $283,4 \mathrm{~b}$ & $433,0 \mathrm{~b}$ & $308,4 \mathrm{~b}$ & $205,9 \mathrm{~b}$ \\
2 & $1067,1 \mathrm{ab}$ & $445,4 \mathrm{ab}$ & $757,6 \mathrm{ab}$ & $395,4 \mathrm{ab}$ & $261,0 \mathrm{ab}$ \\
3 & $1063,2 \mathrm{ab}$ & $366,9 \mathrm{ab}$ & $723,8 \mathrm{ab}$ & $428,6 \mathrm{ab}$ & $288,2 \mathrm{ab}$ \\
4 & $1183,9 \mathrm{a}$ & $549,6 \mathrm{a}$ & $887,9 \mathrm{a}$ & $536,5 \mathrm{a}$ & $411,9 \mathrm{a}$ \\
\hline CV \% & 10,9 & 20,2 & 28,2 & 16,84 & 26,65 \\
\hline
\end{tabular}

Médias seguidas pela mesma letra na mesma coluna não diferem entre si a $5 \%$ de probabilidade pelo teste de Tukey.

Dados encontrados no trabalho de ORRICO JUNIOR et al. (2012), utilizando biofertilizante oriundo dos dejetos de bovinos e suínos para a adubação do capim Piatã nas doses de 100,200 e $300 \mathrm{~kg} \mathrm{ha}^{-1}$ onde os melhores resultados foram obtidos com a maior dose do biofertilizante.

\section{Análise bromatológica}

Para análise de qualidade da forragem, foi considerado somente os teores de proteína bruta, fibra em detergente neutro e fibra em detergente ácido, e as coletas foram feitas de acordo com a maior produção de forragem, considerando assim somente 
três cortes da forragem. Os valores estão na porcentagem sobre a matéria seca do material e encontram-se na tabela 4 .

Tabela 4. Valores de FDN, FDA e proteína (\%) no capim mombaça

\begin{tabular}{|c|c|c|c|}
\hline \multicolumn{4}{|c|}{ Variáveis } \\
\hline & Corte 1 & Corte 2 & Corte 3 \\
\hline Tratamentos & \multicolumn{3}{|c|}{ FDN } \\
\hline 0 & $58.7 \mathrm{a}$ & $63.3 \mathrm{a}$ & $57.6 \mathrm{a}$ \\
\hline 50 & $65.0 \mathrm{a}$ & $64.0 \mathrm{a}$ & $59.9 \mathrm{a}$ \\
\hline 100 & $59.3 \mathrm{a}$ & $71.0 \mathrm{a}$ & $57.9 \mathrm{a}$ \\
\hline 200 & $61.0 \mathrm{a}$ & $73.3 \mathrm{a}$ & $67.3 \mathrm{a}$ \\
\hline \multirow[t]{2}{*}{ CV (\%) } & 6.1 & 7.8 & 2.1 \\
\hline & \multicolumn{3}{|c|}{ FDA } \\
\hline 0 & $35.3 \mathrm{a}$ & $36.0 \mathrm{a}$ & $30.2 \mathrm{a}$ \\
\hline 50 & $32.0 \mathrm{a}$ & $34.9 \mathrm{a}$ & $28.3 \mathrm{a}$ \\
\hline 100 & $35.3 \mathrm{a}$ & $36.8 \mathrm{a}$ & $28.3 \mathrm{a}$ \\
\hline 200 & $30.7 \mathrm{a}$ & $37.5 \mathrm{a}$ & $29.0 \mathrm{a}$ \\
\hline CV (\%) & 13.2 & 4.3 & 5.8 \\
\hline \multicolumn{4}{|c|}{$\mathbf{P b}$} \\
\hline 0 & $3.1 \mathrm{ab}$ & $3.2 \mathrm{c}$ & $3.4 \mathrm{~b}$ \\
\hline 50 & $3.8 \mathrm{a}$ & $3.9 \mathrm{ab}$ & $3.6 \mathrm{~b}$ \\
\hline 100 & $2.5 \mathrm{~b}$ & $4.3 \mathrm{a}$ & $3.3 \mathrm{~b}$ \\
\hline 200 & $2.8 \mathrm{~b}$ & $4.9 \mathrm{a}$ & $4.9 \mathrm{a}$ \\
\hline CV (\%) & 7.4 & 5.0 & 3.3 \\
\hline
\end{tabular}

Médias seguidas pela mesma letra na mesma coluna não diferem entre si a $5 \%$ de probabilidade pelo teste de Tukey; FDN= fibra em detergente neutro; FDA= fibra em detergente ácido.

Observa-se na tabela 4, que para os teores de FDN e FDA, não houve diferença estatística $(\mathrm{P}>0,05)$ entre os parâmetros avaliados. Mesmo não havendo diferença estatística para essas variáveis, notou-se que pelas médias, os teores de FDA foram menores que os teores de FDN, indicando tanto a qualidade como a quantidade de fibra alimentar presente nesse tipo de forrageira, sendo que a Fibra em Detergente Ácido indica a porção não digestível da forrageira.

$\mathrm{O}$ que de acordo com GERON et al., (2012), o teor de FDN dos alimentos representa a fração da fibra não solúvel em detergente neutro, este teor de FDN dos alimentos pode ser utilizado por técnicos e produtores de ruminantes para o balanceamento de rações com teores adequados de fibra alimentar. De maneira geral, tanto a qualidade como a quantidade de fibra alimentar presente nas plantas forrageiras, são parâmetros chaves que podem influenciar na ingestão de matéria seca (MS) pelos animais.

Para os teores de proteína, observa-se que no primeiro corte $\mathrm{o}$ segundo tratamento apresentou diferença entre os demais, fato que pode ser justificado, pois nesse período, foi constatada chuva na região, e isso pode ter influenciado no aumento de proteína. Já para as demais aplicações, aqueles tratamentos que receberam maior dosagem de biofertilizante apresentaram diferenças entre os demais tratamentos, evidenciando a influência do biofertilizante na qualidade da forragem para o teor de proteína.

O trabalho de RUGGIERO et al. (2006), observaram acréscimos nos teores de proteína em função das doses de $\mathrm{N}$ aplicadas somente no período chuvoso e teores menores no mês de julho durante o período seco com cerca 7,3; 8,1 \%. Já Cândido et al. (2005), em 
trabalho realizado em pastagem de capim-mombaça sob manejo de lotação, relataram que o teor de proteína bruta variou em função da duração dos períodos de descanso e dos dias de pastejo, com cerca de 6.3 e 8,5\% PB.

Apesar dos teores de proteínas encontrados nesse trabalho, serem considerados baixos em comparação aos dados de literatura, deve-se levar em consideração que no inicio do experimento a área da pastagem encontrava-se sem nenhum tipo de

\section{CONCLUSÕES}

Conclui-se que a aplicação do biofertilizante é benéfico à produção de pastagens, principalmente se a área já vinha sofrendo falta de manejo adequado. As maiores dosagens de biofertizante/ha ${ }^{-1}$ apresentou melhores resultados, tanto de produtividade

\section{REFERÊNCIAS BIBLIOGRÁFICAS}

ARAÚJO, L. C.; CUNHA, O. F. R.; FERREIRA, E. M.; SANTOS, A. C. Fontes de matéria orgânica como alternativa na melhoria das características químicas do solo e produtividade do capim-Mombaça. Revista Acadêmica Ciências Agrárias e Ambientais, São José dos Pinhais, 65-72 p, 2008.

\section{BARNABÉ, M. C. Produção e composição bromatológica da Brachiaria brizantha cv. Marandu adubada com dejetos líquidos de suínos. 2001. 67f. Dissertação (Mestrado em Ciência Animal)-Universidade Federal de Goiás, Goiânia, 2001.}

CÂNDIDO, M.J.D.; ALEXANDRINO, E.; GOMIDE, C.A.M. et al. Período de descanso, valor nutritivo e desempenho animal em pastagem de Panicum maximum cv. Mombaça sob lotação intermitente. Rev. Bras. Zootec., v.34, p.1459-1467, 2005. manejo, seja corte ou aplicação de fertilizante, dando um indicativo de degradação da área. Com as sucessivas aplicações de biofertilizante, foi observado melhoras na área e na produtividade da forragem e os teores de proteínas podem aumentar com as condições edafoclimáticas da região, principalmente em relação a quantidade de água no solo pela frequência de chuvas e também com um possível manejo no pasto.

quando para a qualidade no teor de proteínas.

As dosagens e o uso do biofertilizante devem ser estudados com cautela e estar de acordo com as disposições ambientais.

EUCLIDES, V. P. B.; VALLE, C. B.; MACEDO, M. C. M.; ALMEIDA, R. G.; MONTAGNER, D. B.; BARBOSA, R. A. Brazilian scientific progress in pasture research during the first decade of XXI century. Revista Brasileira de Zootecnia, v.39, p.151-168, 2010.

FREITAS, K. R. ROSA, B. RUGGIERO, J. A. et al. Avaliação da composição químico-bromatologica do capim mombaca (Panicum maximum) submetidos a diferentes doses de nitrogênio. Bios. J. Uberlândia, v.23, n. 3, p1 -10. July/sept.2007.

GERON, L. J. V.; MEXIA, A. A.; GARCIA, J.; ZEOULA, L. M.; GARCIA, R. R. F.; MOURA, D. C. Desempenho de cordeiros em terminação suplementados com caroço de algodão (Gossypium hirsutum L.) e grão de milho moído (Zea mays L.). Archives of Veterinary Science, Curitiba, v. 17, n.4, p. 34 - 42, 2012. 
GOMES, M. A. Efeitos de intensidade de pastejo e períodos de ocupação da pastagem na massa de forragem e nas perdas de valor nutritivo da matéria seca do capim Mombaça (Panicum maximum Jacq. Cv Mombaça). São Paulo: Faculdade de Zootecnia e Engenharia de Alimentos, 2001. 112p. Dissertação (Mestrado em Zootecnia) Universidade de São Paulo, 2001.

HANISCH, A. L. FONSECA, J. A. Características produtivas e qualitativas de sete forrageiras perenes de verão sob adubação orgânica e mineral. Revista Verde (Mossoró - RN - Brasil), v.6, n. 4, p. 01. 2011.

ORRICO JUNIOR, M.A.P.; CENTURION, S.R.; ORRICO, A.C.A.; SUNADA, N.S. Effects of biofertilizer rates on the structural, morphogenetic and productive characteristics of Piatã grass. Revista Brasileira de Zootecnia. 41: 1378-1384, 2012.

RUGGIERO, J.A.; ROSA, B.; FREITAS, K.R. et al. Avaliação de lâminas de água e de doses de nitrogênio na composição bromatológica do capim-mombaça. Biosci. J., v.22, p.9-19, 2006

SILVA, D. J., QUEIROZ, A. C. Análise de alimentos: método químicos e biológicos. Viçosa: Editora Universitária. 2002. 235 p.

SCHEFFER-BASSO, S. M.; SCHERER, C. V.; ELLWANGER, M. de F. Resposta de pastagens perenes à adubação com chorume suíno: pastagem natural. Revista Brasileira de Zootecnia, v. 37, n. 2, p. 221-227, 2008.

TINOCO, A.F.F.; DINIZ, M.C.N.M.; SILVA JUNIOR, F.O.; MEDEIROS, H.R.; GALVÃO, A.Y.S. Características morfológicas e crescimento do campimmombaça submetido a diferentes alturas de corte, sob irrigação. Revista Verde, v.4, n.1, p. 114-119, 2009.

VAN SOEST, P. J . Use of detergents in the analysis of fibrous feeds. A rapid method for the determination of fiber and lignin. Journal of the Association Official Agricultural Chemists, v. 46, n. 5, p. 829-835, 1963.

VAN SOEST, P. J.; ROBERTSON, J. B.; LEWIS, B. A. Symposium: carbohydrate metodoloy, metabolism, and nutritional implications in dairy cattle. Methods for dietary fiber, neutral detergent fiber, and nonstarch polysaccharides in relation to animal nutrition. Journal of Dairy Science, Madison, v. 74, n. 10, p. 3583-97. 1991. 